Tropical Journal of Pharmaceutical Research October 2019; 18 (10): 2183-2187

ISSN: $1596-5996$ (print); 1596-9827 (electronic)

(C) Pharmacotherapy Group, Faculty of Pharmacy, University of Benin, Benin City, 300001 Nigeria.

Available online at http://www.tjpr.org

Original Research Article

http://dx.doi.org/10.4314/tjpr.v18i10.26

\title{
Iron deficiency anemia and associated factors among pregnant women in a tertiary care hospital, in Sargodha District, Pakistan
}

\author{
Sumbul Qamar ${ }^{1}$, Saira Azhar ${ }^{2 \star}$, Saadoon Mazhar ${ }^{3}$, Khush Bakht ${ }^{4}$, Ghulam \\ Murtaza $^{5}$ \\ ${ }^{1}$ Department of Pharmacy, COMSATS University, Islamabad (Abbottabad campus), ${ }^{2}$ College of Pharmacy University of \\ Sargodha, ${ }^{3}$ Department of Radiology, Lahore General Hospital, ${ }^{4}$ Department of Medicine, Fauji Foundation Hospital Lahore, \\ ${ }^{5}$ Department of Pharmacy, COMSATS University, Islamabad (Lahore Campus), Pakistan
}

*For correspondence Email: gmdogar356@gmail.com, saira.azhar@uos.edu.pk; Tel: +92-314-2082826; Fax: +924299204787

Sent for review: 13 December 2018

Revised accepted: 25 September 2019

\begin{abstract}
Purpose: To evaluate iron deficiency anemia and other concomitant risk factors among pregnant women in a tertiary care hospital in Sargodha District of Pakistan.

Methods: An observational cross-sectional study on pregnant women over a six-month period from December 2016, was conducted in the gynaecology and obstetrics department of the District Headquarters Hospital, Sargodha, Pakistan. All women with renal failure, heart disease and surgical history were excluded from the study, while all pregnant women visiting the out-patient department $(O P D)$ were included in the investigation. Blood sampling and analysis were performed, following standard laboratory operating procedures to determine the haemoglobin $(\mathrm{Hb})$ levels of the patients.

Results: Fifty pregnant women were enrolled in this study. They had a mean age of $27.85 \pm 4.99$ years with a range of $20-46$ years. Almost half, i.e., 26 (52\%), were aged $20-30$ years; 18 (36 \%) $31-40$ years and six (12\%) > 40 years of age. Regarding occupational status, $45(90 \%)$ of the respondents were housewives. In total, $86 \%$ of the women were anemic, while the remaining $14 \%$ were non-anemic and had an $\mathrm{Hb}$ level slightly > 11 $\mathrm{g} / \mathrm{dL}$. Among the anemic women, 13 (26\%) had mild anemia, 33 (66 $\%)$ moderate anemia, and 4 (8\%) were severely anemic.

Conclusion: Iron deficiency and anemia have major health impacts on pregnant women. Steps should be taken during ante-natal care to monitor $\mathrm{Hb}$ levels in pregnant women and apply appropriate remedy where necessary. Other biomarkers and related risk factors such as total iron binding capacity (TIBC) and total blood count (TBC) have previously been found to be linked to anemia.
\end{abstract}

Keywords: Anemia, Biomarkers, Total blood count (TBC), Hb levels, Pregnancy, Maternal morbidity and mortality, Iron deficiency

This is an Open Access article that uses a fund-ing model which does not charge readers or their institutions for access and distributed under the terms of the Creative Commons Attribution License (http://creativecommons.org/licenses/by/4.0) and the Budapest Open Access Initiative (http://www.budapestopenaccessinitiative.org/read), which permit unrestricted use, distribution, and reproduction in any medium, provided the original work is properly credited.

Tropical Journal of Pharmaceutical Research is indexed by Science Citation Index (SciSearch), Scopus, International Pharmaceutical Abstract, Chemical Abstracts, Embase, Index Copernicus, EBSCO, African Index Medicus, JournalSeek, Journal Citation Reports/Science Edition, Directory of Open Access Journals (DOAJ), African Journal Online, Bioline International, Open-J-Gate and Pharmacy Abstracts

\section{INTRODUCTION}

According to a WHO report, iron deficiency anemia contributes to half of all anemia cases. The developed and developing countries are extensively being affected by this disorder, consequently having bad effects on mothers as well as fetus health [1]. Consequences resulting from anemia have severe impacts on the health, economic development and social development 
of women [2]. Globally, this disease affects 41.8 $\%$ of pregnant women, with the highest occurrence being reported in Africa with 17.2 million cases [3].

Iron deficiency is the most widely recognised cause for nutritional anemia in the world, identified as a major public health problem globally, specifically in emerging countries. Infants, children [4], adults [5] and women particularly pregnant women - are often influenced by iron deficiency anemia. Overall, 468.4 million women of childbearing age are anemic. In the emerging countries, nearly half the population is anemic (mostly pregnant women and children) [6]. WHO defines anemia as having a hemoglobin level below $11 \mathrm{~g} / \mathrm{dl}$ for pregnant women. Furthermore, the ranges of mild anemia is $10.0-10.9 \mathrm{~g} / \mathrm{dl}$, moderate anemia is $7-9.9 \mathrm{~g} / \mathrm{dl}$ and severe anemia is $<7 \mathrm{~g} / \mathrm{dl}$ [2].

The prevalence of anemia reported in various studies ranges between 16.6-95\% [7-10]. All pregnant women with low $\mathrm{Hb}$ levels are constantly at a higher risk for maternal morbidity and mortality as well as sever anemic conditions. Furthermore, the iron deficiency, alongside anemia, may not only affect the mother but the neonate, with low birth weight (LBW), prenatal mortality and preterm delivery [8]. Anemia among pregnant women has multi-factorial causes including low iron level. Other factors such as intestinal parasitic infections, chronic illness and biomarkers like total leukocytes count (TLC) and total iron binding capacity (TIBC) have a major role in the progression of the disease [12].

As indicated by an investigation study in Pakistan, the outcomes demonstrated that the ratio of anemia was greater in rural regions when compared with urban ones. The anemic ratio was higher (i.e., $72.75 \%$ ) in the women with ages between $30-37$. As indicated by the frequency of anemia in the three trimesters, the anemia level was higher (i.e., $81.9 \%$ ) in the third trimester, than in the second trimester (at 61.3 $\%)$, followed by the first trimester (58.6\%). Uneducated women had a greater anemic ratio as compared to the educated women [13]. Additionally, about half of the women with anemia were living in the subcontinent of India. Out of these, the percentage of women who developed anemia during pregnancy was $88 \%$ [14]. In urban areas of Pakistan, the occurrence of anemia was $90.5 \%$ in pregnancy. Among them, $0.7 \%$ cases were related to severe anemia [15] and $56 \%$ of the maternal deaths were owed to anemia [14].
The fundamental aim of this investigation was to assess the occurrence of iron deficiency anemia and other concomitant risk factors among pregnant women in a tertiary care hospital in the Sargodha district of Pakistan.

\section{EXPERIMENTAL}

An observational cross-sectional study was conducted on pregnant women over a six-month period, starting from December 2016, in the District Headquarters Hospital of Sargodha. All pregnant females with renal failure, heart disease and surgical history were excluded from the study. Pregnant women visiting the outpatient department (OPD) were enrolled in the study. Demographic information was collected along with all other required diagnostic values. All standard operating procedures were followed. The blood was drawn from the anticubital vein with the help of a laboratory technician, stored in the EDTA tubes and then analysed for hemoglobin, serum iron and TIBC. Other blood parameters such as total leukocyte count, neutrophils, lymphocytes, monocytes, eosinophils, basophils and platelets were determined. Blood sampling was done using SYSMAX hematology analyser. This study was performed in accordance with international guideline for human use in scientific studies [16]. Ethical approval (no. 2014/PHM/53) was obtained from the Hospital Ethical Committee. Moreover, the patients were clearly informed about the study before sample collection and before providing any information. Furthermore, they were informed that their personal information was only being gathered for research purposes and would be kept confidential. Moreover, to fulfil ethical requirements, a verbal and written consent was obtained from each respondent.

\section{Statistical analysis}

All gathered information was saved by electronic means and analysed through SPSS version 20. Mean and standard deviation were calculated by applying descriptive statistics. Frequency distribution and percentages were analysed for variables like hemoglobin level, serum iron and TIBC. Overall, a p-value of less than 0.05 was considered as statistically significant.

\section{RESULTS}

A total sample consisting of 50 pregnant women was recruited for this study. The mean age of respondents was $27.85 \pm 4.99$ years with a range of $20-46$ years. Of these, 26 (52\%) were in the age group of $20-30,18$ (36\%) were $31-$ 
40 and 6 (12\%) were over 40 years. Regarding working status, 45 (90 \%) females were housewives and the rest $5(10 \%)$ were working as either attendants in schools or as house cleaners. Their education status showed that about half, i.e., 25 (50\%), were of primary level or lower.

The demographic characteristics of the women are shown in Table 1. The mean level of serum iron in the women was $37.58+5.71 \mu \mathrm{g} / \mathrm{dL}$ while $\mathrm{Hb}$ level was $8.8+1.52 \mathrm{~g} / \mathrm{dL}$ and the average TIBC was $329+31.23 \mu \mathrm{g} / \mathrm{dL}$. Mean TLC in the women's serum was $10681+5464$. Further details about total blood cell (TBC) count are given in Table 2. The proportion of women found to be anemic was $86 \%$, while the remaining 14 $\%$ were non-anemic with $\mathrm{Hb}$ level close to 11 $\mathrm{g} / \mathrm{dL}$. Among all the anemic women, $13(26 \%)$ had mild anemia, $33(66 \%)$ moderate anemia and $4(8 \%)$ were severely anemic.

Table 1: Demographic characteristics of pregnant women $(n=50)$

\begin{tabular}{lc}
\hline Variable & $\mathbf{n}(\%)$ \\
\hline Age & $26(52 \%)$ \\
$20-30$ & $18(36 \%)$ \\
$31-40$ & $6(12 \%)$ \\
$\quad$ Above 40 & \\
Education & $25(50 \%)$ \\
$\quad$ Primary and below & $15(30 \%)$ \\
$\quad$ Secondary & $10(20 \%)$ \\
$\quad$ Tertiary & \\
Socioeconomic status & $22(44 \%)$ \\
$\quad$ Low & $18(36 \%)$ \\
$\quad$ Medium & $10(20 \%)$ \\
High & \\
Occupation & \\
Housewife & $45(90 \%)$ \\
$\quad$ Working women & $5(10 \%)$ \\
\hline
\end{tabular}

Table 2: Total blood count for pregnant women

\begin{tabular}{lc}
\hline TBC & Mean \pm SD \\
\hline Serum & $37.58 \pm 5.71$ \\
Iron $(\mu \mathrm{g} / \mathrm{dL})$ & $328.66 \pm 31.23$ \\
TIBC $(\mu \mathrm{g} / \mathrm{dL})$ & $8.88 \pm 1.52$ \\
$\mathrm{Hb}(\mathrm{g} / \mathrm{dL})$ & $10681.60 \pm 5648.58$ \\
$\mathrm{TLC}$ & $61.06 \pm 16.40$ \\
Neutrophils & $29.50 \pm 14.85$ \\
Lymphocytes & $5.46 \pm 2.47$ \\
Monocytes & $2.42 \pm 1.88$ \\
Eosinophil & $1.28 \pm 0.75$ \\
Basophils & 0 \\
Immature cell & Nill \\
Virocytes & $339500 \pm 153287$ \\
Platelets & \\
\hline
\end{tabular}

Key: Total blood count (TBC), total iron binding capacity (TIBC), hemoglobin (Hb), Total leukocyte count (TLC)

\section{DISCUSSION}

The investigation planned to evaluate the occurrence of iron deficiency anemia and other concomitant factors in pregnant women. All pregnant women with low $\mathrm{Hb}$ levels, as compared to normal women, were included in the study. There was a very high prevalence of anemia in our respondents. As per the WHO classification scale, most participants were moderately anemic. These findings were supported by the study findings from research conducted in other developing such as Ethopia [17].

The high occurrence of iron and other micronutrient inadequacies among women before and during pregnancy in unindustrialised countries is a matter of concern; the perinatal mortality and morbidity is significantly related to maternal anaemia [18].

Anaemia is a public issue during pregnancy in most unindustrialised countries. Pregnancy results greatly vary depending on its sort and seriousness. Despite the relationship between iron deficiency anemia in pregnancy and unfavorable perinatal results having been examined widely, the literature is quiet contradictory. It has been accounted for that maternal iron deficiency before mid-pregnancy is related to an expanded danger of pre-term delivery, but other specialists have found no relationship between anaemia in the last trimester and hostile pregnancy consequences. However, major parts of these studies were not capable in evaluating anaemia owed to the severity of the illness [19].

The reason of high prevalence of anemia is associated to the socioeconomic status of the families and dietary patterns. The socioeconomic status of the family or household are directly related to the anemic condition of pregnant women. Families with low socioeconomic status had a higher anemic prevalence, as compared to moderate and high socioeconomic status. The present results are supported by other published findings from India, Nigeria and Ethiopia [20-22]. This may be owed to the inability of the pregnant women to buy good quality food and adopt good eating habits. Sociodemographic factors such as social class, occupational status and educational status are related to the prevalence of anemia in pregnant women [23].

Thus, a constant iron supplementation along with dietary diversification is required for pregnant women during pregnancy. This combination is 
more desirable in communities with diets with a low bioavailability of iron [24].

\section{Limitations of the study}

A primary limitation of this work is the small sample size; thus, this study cannot be generalised to other cities of Pakistan.

\section{CONCLUSION}

Iron deficiency anemia has a major health impact on pregnant women. Other biomarkers and related risk factors such as TLC, serum iron and TIBC have previously been reported found to be linked with anemia. Little is known about the impact of pregnant mothers' iron status on their well-being and the development of the newborn child, as well as on the mothers' quality of life. These issue warrants detailed investigation.

\section{DECLARATIONS}

\section{Acknowledgement}

One of the authors, Sumbul Qamar, a recipient of Higher Eductaion Commission (HEC) scholarship, is grateful to HEC, Pakistan for the financial support of this work.

\section{Conflict of interest}

No conflict of interest related with this study.

\section{Contribution of authors}

We declare that this work was done by the authors named in this article and all liabilities pertaining to claims relating to the content of this article will be borne by the authors. Sumbul Qamar conceived the paper, drafted the outline and wrote the draft of the article. Saira Azhar reviewed and edited the manuscript. Saadon Mazhar and Khush Bakht reviewed and contributed in detail analysis of the lab findings of the patients. Ghulam Murtaza reviewed the manuscript and provided his valuable comments to improve it and contributed towards the finalization of manuscript.

\section{Open Access}

This is an Open Access article that uses a funding model which does not charge readers or their institutions for access and distributed under the terms of the Creative Commons Attribution License (http://creativecommons.org/licenses/by/ 4.0) and the Budapest Open Access Initiative (http://www.budapestopenaccessinitiative.org/rea d), which permit unrestricted use, distribution, and reproduction in any medium, provided the original work is properly credited.

\section{REFERENCES}

1. World health organization. Worldwide prevalence of anemia 1993-2005. WHO Global Database on Anemia. Geneva: World Health Organization; 2008.

2. Allen LH. Anemia and iron deficiency: effects on pregnancy outcome. Am J Clin Nut 2000; 71(5): 1280S$1284 S$.

3. Benoist B, McLean E, Cogswell M, Egli I, Wojdyla D. Worldwide prevalence of anemia, WHO Vitamin and Mineral Nutrition Information System, 1993-2005. Public Health Nutr Geneva. 2008; 12(4): 444-454.

4. Ali $A$, Fathy $G A$, Fathy $H A$, Abd El-Ghaffar $N$. Epidemiology of iron defeciency anaemia: effect on physical growth in primary school children, the importance of hookworms. Int $J$ Acad Res 2011; 3(1): 495-500.

5. Idris M. Iron deficiency anaemia in moderate to severely anaemic patients. Journal of Ayub Medical College, Abbottabad: JAMC. 2005; 17(3): 45-47.

6. Hercberg S, Galan P. Nutritional anaemias. Ballière's Clin Haematol 1992; 5(1): 143-168.

7. Ouma P, Van Eijk AM, Hamel MJ, Parise M, Ayisi JG, Otieno $K$, Kager $P A$, Slutsker L. Malaria and anaemia among pregnant women at first antenatal clinic visit in Kisumu, western Kenya. Trop Med Int Health 2007; 12(12): 1515-1523.

8. Haggaz AD, Radi EA, Adam I. Anemia and low birth weight in western Sudan. Trans $R$ Soc Trop Med Hyg 2010; 104(3): 234-236.

9. Jufar $A H$, Zewde T. Prevalence of Anemia among Pregnant Women Attending Antenatal Care at TikurAnbessa Specialized Hospital, Addis Ababa Ethiopia. J Hematol Thrombo Dis 2013; 2(1): 1-6.

10. Obse N, Mossie A, Gobena T. Magnitude of Anemia and Associated Risk Factors among Pregnant Women Attending Antenatal Care in Shalla Woreda, West Arsi Zone, Oromia Region, Ethiopia. Ethiop J Health Sci 2013; 23(2): 165-173.

11. Uneke CJ, Duhlinska DD, Igbinedion EB. Prevalence and public-health significance of HIV infection and anemia among pregnant women attending antenatal clinics in south-eastern Nigeria. J Health Popul Nutr 2007; 25(3): 328-335.

12. Tolentino K, Friedman JF. An update on Anemia in Less Developed Countries. Am J Trop Med Hygiene 2007; 77(1): 44-51.

13. Ullah I, Zahid M, Khan MI, Shah M. Prevalence of Anemia in Pregnant Women in District Karak Khyberpakhtunkhwa, Pakistan. Int J Biosci 2013; 3: 7783. 
14. Anjum A, Manzoor M, Manzoor N, Shakir HA. Prevalence of anemia during pregnancy in district Faisalabad, Pakistan. Punjab Univ J Zool 2015; 30(1): 15-20.

15. Naz H, Begum B. Prevalence and associated risk factors of anaemia in pregnant women in a teaching hospital, Korangi Industrial Area. Pak J Surg 2013; 29(2): 131 133.

16. The World Medical Association. Declaration of Helsinki [Web Page] 2004. Available at http://www.wma. net/e/policy/b3.htm.

17. Gedefaw L, Ayele A, Asres Y, Mossie A. Anemia and associated Factors among pregnant women attending antenatal care clinic in Wolayita Sodo Town, Southern Ethiopia. Ethiop J. Health Sci 2015; 25 (2): 155-164.

18. Cutner A, Bead R, Harding J. Failed response to treat anaemia in pregnancy: reasons and evaluation. J Obstet Gynecol 1999: 23-27.

19. Kidanto HL, Mogren I, Lindmark G, Massawe S, Nystrom L. Risks for preterm delivery and low birth weight are independently increased by severity of maternal anemia. S Afr Med J 2009; 99(2): 98-102.
20. Ivoke N, Eyo EE, Ivoke ON, Nwani CD, Odu EC, Asogha $C N$. Anemia prevalence and associated factors among women attending antenatal clinic in south western Ebonyi State, Nigeria. Int J Med Med Sci 2013; 46(1): 1354-1359.

21. Bisoi S, Haldar D, Majumdar TK, Bhattacharya N, Sarkar GN, Ray SK. Correlates of anemia among pregnant women in a rural area of West Bengal. J Fami Welfa 2011; 57(1).

22. Belachew $T$, Legesse $Y$. Risk factors for anemia among pregnant women attending antenatal clinic at Jimma University Hospital, southwest Ethiopia. Ethiop Med J 2006; 44(3): 211-220.

23. Sukrat $B$, Suwathanapisate $P$, Siritawee $S$, Poungthong $T$, Phupongpankul K. The prevalence of iron deficiency anemia in pregnant women in Nakhonsawan, Thailand. J Med Assoc Thai 2010; 93(7): 765-770.

24. Stoltzfus RJ, Dreyfuss ML, Chwaya HM, Albonico M. Hookworm control as a strategy to prevent iron deficiency. Nutr Rev 1997: 55(6): 223-232. 